\title{
THE ROLE OF PLAYERS AS INNOVATORS
}

\author{
$\begin{array}{llll}\text { I. TURCU } & \text { D.E. COSTIN } & \text { L.D. PĂSĂRIN } & \\ & \text { R. DUMITRU } & \end{array}$ \\ M.G. POPA ${ }^{3}$ M.C. POPESCU ${ }^{3}$ M.C.R BARBU ${ }^{3}$
}

\begin{abstract}
Sport teaches you to fight for your goal and not to be harmed in the moments of balance. The psyche feeds on the desire for recognition, selftranscendence and progress; consequently, once the taste for small victories has settled and the desire to overcome barriers exists, the ambition to achieve the set goals appears. Ambition means pursuing a goal and the desire to do everything in your power to achieve it. In the paper "The role of players as innovators" we aimed to present first of all the social dimension of sport, why it has become so important nowadays, as well as the reasons why we consider athletes to be innovative. In the last part are presented a series of athletes considered innovators or pioneers, each in the sport they practice, because they managed to stand out and have exceptional results.
\end{abstract}

Key words: role, social dimension, athlete, innovation.

\section{Introduction}

Practicing a performance sport means strength, endurance, mental endurance and character. All these qualities of an athlete are acquired throughout life, along with the challenges they are exposed to, the choices they make and the path they want to follow.

But how do athletes manage to be so strong emotionally or mentally? We all know that behind a performance athlete are years of work, but there are also many values and lessons learned from the sport he practices.

Therefore, personal development is a continuous process of evaluating the qualities and setting goals, and the role of sport is to create the complete personality of the individual.

Sport is one of the phenomena that characterizes the modern and contemporary era. This fact is due both to the pleasure of outdoor movement and to the continuous desire to improve and exceed one's own psycho-physical limits [9]. Through the developed complexity, sport can be understood as social structures and processes that determine on the one hand the conditions for carrying out exercises as fun, regulating the mechanism through technique; on the other hand, the organization of sport from an institutional point of view is fixed [3].

\footnotetext{
${ }^{1}$ Department of Motric Performance, Transilvania University of Braşov.

2 Department of Individual Sports and Kinetotherapy, Dunărea de Jos University of Galați.

3 Department of Theory and Methodology of Motor Activities, University of Craiova.
} 
The current development of the sport seems to be an extension of the game, as it has been practiced for a long time. Traditional societies frequently codified their physical games from everyday activities such as hunting, fishing, wrestling, running, swimming, throwing, and incorporated them into local or largescale competitions. These competitions involved a special organization and a venue specially reserved for this purpose. The existence of competitions, training and stadiums is by no means a feature of the modern era [5]. But the study of sports competitions in various societies has revealed that contemporary sport is an indissoluble phenomenon related to social development. Industrialization and urbanization, the existence of social groups characterized by a high standard, both economic and cultural, widespread schooling, the extent of mass media, have had the effect of diversifying and specializing athletes, increasing performance, generalizing the show and competition [15].

\section{Literature review}

\subsection{What is sport as a social phenomenon?}

Sport is an integral part of human culture. Sports activities contribute to physical improvement, personal development and society as a whole. Through physical training, the needs not only for entertainment, play and socializing, but also for other types of social activities are met [2].

Sports activities are based on targeted activities related to physical activity. The inclusion of the individual in physical education and sports contributes to socialization, forms the skills and abilities that are important for other activities. This applies in particular to those sports in which a person acts in a team.

Sport is a whole complex of material and spiritual values of social importance. This set includes, in particular, sports facilities for mass training and monitoring of sports competitions. In modern society, stadiums and other sports complexes become part of the architectural aspect of cities, forming an infrastructure for recreation and tourism.

The spiritual values of sport include information support for athletes' activities, the advertising industry, and works of art, which reflect different aspects of sports life. The spiritual component of physical culture and sport is also reflected in the formation of ethical norms that are widely distributed in society.

Events in society do not occur in isolation, but are closely linked to each other. For this reason, physical culture fulfils many different social functions, of which the integration function can be considered the main one [16]. In this sense, sport is a means of uniting people as a whole and identifying an individual with a team. Both athletes and fans during the competition are part of a certain cohesive community.

Sport acquired a special social significance at the end of the 20th century, as evidenced by the increased interest in organizing world tournaments, championships and Olympic Games. Going internationally, sport contributes to the strengthening of international relations and even becomes an instrument of policy between individual states [11]. Sports teams are transformed into friendly embassies.

The conscious use of sport in politics expands its social functions, creates conditions for strengthening the national dignity and prestige of the country in the world community. Very often, sport is used as a means of conducting election campaigns. 
Political parties actively attract famous athletes. This cooperation enhances the importance of political unification in the eyes of voters [6].

Sport has come to have all these valences due to its global popularity and the force majeure it has in promoting the importance of movement for different aspects of the life of a person, a community or a society [19].

Thus emerged the concept of sport for social impact, which in a broader definition is the ways in which sport and physical education can be used consciously and intentionally as part of interventions that solve major problems such as pollution, discrimination, poor health, access to education, lack of civic involvement [10]. Although we most often look at sports activities with a hat of performance, of large global competitions, of well-known athletes, sport for social impact has a size at least as consistent, only that it is often marginal to sports activities assimilated to sport of performance. A concrete case are children's football tournaments that aim to develop sports skills, but end up developing children's skills such as mutual respect, teamwork or the idea of fair play.

\subsection{Reasons why sports players are seen as innovative}

Since ancient times, but especially in the second half of our century, performance athletes have been models to which the world of children has always referred.

In the modern era, the media has contributed the most to the circulation of the example offered by these last romantic heroes. The great athlete displays extraordinary qualities, in order to achieve high performance, he makes an extraordinary motor gesture; the gymnast, for example, performs perhaps the most difficult, formidable act, because at the moment of the exercise he denies the very principle of verticality [18]. Such a show, performed at a high level, becomes lavish and fascinating. In the curious and sensational eyes of the young man in training, the athlete thus becomes, in addition to the object of attraction, a model. We can differentiate these models:

- Physical model. It is known that the human model also involves the aesthetic dimension of the personality, the man feeling the permanent need for beauty. Or, as a rule, the athlete has a harmonious physique, scope and harmony of plans, segments, and movement - so he is a beautiful being. Even just the way bodybuilding has conquered young age in our years shows that this model, the somatic model, is attractive and proliferating. Especially when beauty is combined with the extraordinary (in gymnastics, underwater swimming and other popular disciplines) this combination amplifies the amazement and intensifies the grip [16].

-Ethical model. The sports act is available to anyone. To achieve this extraordinary effect requires not only genetic endowment, but also often strenuous efforts, a long process of improvement. In order to be able to work 10-15 hours a day, 24 hours a day, throughout the competitive life, the athlete - obviously superior physically equipped - must also have a power of patience, to postpone the joys of adolescence and youth, in favour of concentrating his entire energies to repeat the exercise until the automation that ensures the performance [10]. Whoever succeeds in all this means that he has a healthy, stannic morality, so he is also an ethical model. 
- Social model. As a bearer of ideas (he embodies Work, Honesty, Ambition, he represents the Country, he is a messenger of Peace), the great performer also becomes a social model. He does not livein isolation, he lives in a climate, and he has an affiliation, an integration - which influences him, which he represents in the world.

All those who develop some skills based on vocations discovered personally or by someone else should be role models for those around them. They are models; first of all, in terms of the qualities they have to perform: perseverance, ambition, courage, determination, even certain renunciations of the temptations of a life free from any pressures and constraints [17].

Athletes are to be admired, first of all, because they value some skills and enter an extremely tough competitive system, on the one hand, but which also puts them in a position to become at some point people admired on all over the globe whether they are Olympic, world or even national champions.

Unfortunately, the spectacular appearance is less visible in the current activity of an athlete. The visible aspect for everyone appears after the moment of climbing the podium, when he gets the medal.

\section{Ambition, determination and perseverance}

Athletes teach you to fight for your goal and not let yourself be harmed in the moments of balance. The psyche feeds on the desire for recognition, selftranscendence and progress; consequently, once the taste for small victories has settled and the desire to overcome barriers exists, the ambition to achieve the set goals appears [14]. Ambition means pursuing a goal and the desire to do everything in your power to achieve it.

Determination and perseverance are qualities that all great athletes possess and without which they could not overcome failures and defeats.

\section{Motivation and endurance}

The top athletes, the ones we know and love and the ones we support in front of the TVs, for medals and moments of glory, have experienced countless defeats. But for most of them, failure means the motivation to surpass yourself, to break personal records and to prove that, in addition to physical training, there is an unwavering psyche.

\section{Social abilities}

Especially when we talk about team play, there is a need for collaboration between all its members [13]. Suddenly, the athlete is no longer just the individual, but a unitary whole - the whole team. In order to succeed together, we need collaboration, communication and coordination. All these skills are learned in a team. Players need to strengthen and share the relationships with the fan base using communications apps [4]. Athletes have understood how important is their online presence, that's why they recorded large numbers of followers on their Facebook and Twitter accounts [7].

\section{Self-confidence and discipline}

Self-confidence is gradually cultivated, with small personal victories, i.e. results. Also, in sports, as in art, discipline is an education you receive as a child, and at some point it will become a way of life. Not many people can get up and start 
again and again an exercise, a movement, a throw, until they have performed it so many times, that it becomes like a second nature.

\section{Leadership}

The ability to mobilize a group of people towards a common goal, to inspire them, to guide them and to make decisions that lead to evolution - are just a few characteristics of leadership [8]. The role of leaders is very important in a group. It can have an impact on team dynamics, unity and satisfaction. Leadership must be practiced; it cannot be learned only on a theoretical level [1]. Therefore, through athletes it contributes significantly to the development of these skills and prepares the individual from a practical point of view for a lot of situations that can be easily transposed in personal or professional life [12].

\section{Findings and Discussions: Athletes who} have been seen as Innovators and Pioneers in the World of Sports

\section{Olga Korbut - a new era in women's artistic gymnastics}

Nicknamed the "Minsk Sparrow", she won four gold medals at the 1972 and 1976 Summer Olympics, where she competed in the Soviet Union.

She participated in the 1972 Olympic Games in Munich, from where she returned with three gold medals: team, beam and ground. Get the silver at uneven parallels. However, after an unexpected failure in the parallel bars, she lost the Olympic title in the individual competition composed in favour of her teammate, Ludmilla Tourischeva. Receives the title of "Athlete of the Year" from ABC Wide World of Sports.
At the 1976 Montreal Olympics, she is overshadowed by the performances of Romanian Nadia Comăneci and her teammate, Nellie Kim. However, he gets the gold on the teams and the silver on the beam.

In her career, he also won gold medals for teams and jumping at the World Championships in Varna, 1974. Also, there she won four silver medals in All Around, unequal parallels, beam and ground. In 1977, she finished her studies at the Pedagogical Institute in Grodno, becoming a teacher.

\section{Nadia Comaneci - the first perfect ten}

Nadia Comăneci, the first gymnast in the world to receive the tenth grade at an international gymnastics' competition, was born on November 12, 1961 in Oneşti, Bacău County.

Nadia Comăneci's record shines with five Olympic gold medals, two gold medals at the World Championships and nine gold medals at the European Championships. The total number of medals won by Nadia Comăneci at the Olympics, CM and CE amounts to 25, of which 16 gold. She is considered one of the best sportswomen of the last century and one of the greatest gymnasts in the world.

But Comaneci, like Korbut, was also an acrobatic innovator. It has two elements named for it, including an open front jump to unequal parallels - which is still worth an E rating under the current set of rules.

\section{Svetlana Khorkina - a unique path to success}

Svetlana Khorkina's revolutionary style has definitely changed gymnastics. Khorkina's long legs and slender physique meant she had to invent special exercises 
for her. The Russian woman's creativity led to eight elements bearing her name named in the point's code. Two jumps, three elements at unequal parallels, two elements on the beam and a jump to the ground.

Her unique style of uneven parallels has helped her dominate the device for almost a decade. She won her last world title in 2003, eight years after winning her first title.

Khorkina has won seven Olympic medals, as well as dozens of world and European medals. The 20 medals obtained at the World Championship are matched only by Simone Biles.

\section{Nastia Liukin - combining difficulty and execution in open point}

The first woman to win the Open Score Olympic Games, Nastia Liukin, proved that mastery and execution can still be combined to succeed in a set of rules focused on great difficulties.

For Liukin, the daughter of Olympic champion Valeri Liukin and world rhythmic gymnastics champion Anna Liukin, sometimes Olympic gold seemed to be destiny. It was a miracle, growing rapidly through the ranks of US juniors. Although she was too young to compete in the 2004 Athens Olympics, Liukin's scores at the 2004 U.S. Championships would have placed her third in the senior competition.

Liukin, 19, persevered until the 2008 Beijing Olympics. In a fairy-tale competition, Liukin gave her best when beating American rival and world champion Shawn Johnson, who dominated the competition. Nastia Liukin became the third woman in the USA to win the Olympic gold medal. She continued to win medals in three of the four finals of the individual apparatus.

\section{Hulk Hogan - The story of the most famous wrestler of all time}

When you say Hulk Hogan you mean wrestling and vice versa. The famous superstar made a sensation in the 80 's and is considered a pioneer of the phenomenon. He is the man who paved the way for wrestlers to become famous.

Hogan is considered by many to be the greatest professional wrestler of all time. According to IGN, he is "the most famous superstar in the world and the most popular fighter of the 1980s." Hogan enjoyed considerable popularity between 1984 and 1993 as a star in the World Wrestling Federation (WWF, now WWE), which continued throughout the 1990s in World Championship Wrestling (WCW), where in 1996 he became -a megastar and in the leader of the National World Order (Won) "Hollywood", Hulk Hogan.

\section{Michael Jordan}

When Jordan was selected for the Chicago Bulls, the latter was a losing team that managed to gather only 600 fans at home games. Jordan changed the situation very quickly. His style of play and the fierce spirit of the competition reminded fans of Julius Erving (1950-), who had been a superstar player in the 1970s. The way Jordan jumped to throw the ball to the basket quickly filled the stands of fans during league matches. In his first season he was named to the AllStar team and later, he was honoured with the title "Rookie of the Year" of the league.

Michael Jordan focused on improving other skills in his basketball game and in 1988 was named "Defensive Player of the Year". He was also named "the most 
valuable player in the league" and became the first player to lead the league in scoring.

In 2003, Michael Jordan retired from basketball after a glorious 19-year career after winning six NBA titles with his team.

\section{Johan Cruyff}

Johan Cruyff remains one of the most intelligent and innovative personalities in the history of the sport, standing out through his vision on the tactical organization of the football game. From the very beginning, as a player, Johan Cruyff emphasized the importance of mental aspects in capitalizing on his sporting potential, trained his mind and thus allowed his remarkable creativity to highlight his sporting qualities. Later, he became the manager who revolutionized football, through the approach and organization of the game. Thus, he left his mark on the sporting and human evolution of some top footballers, such as Pep Gurdiola, Ronald Koeman, Michael Laudrup, Gică Popescu or Gică Hagi.

\section{Ronnie O'Sullivan}

Ronnie O'Sullivan is one of the best players in the history of snooker and is among those who have turned this elite sport into a global one. The Englishman was delighted by his talent, his extraordinary speed of thought and the ease with which he overcame his opponents.

Ronnie O'Sullivan has always managed to attract attention and be loved even the hard moments of his career. Ronnie's fans never regretted the choice he made, and the nonchalance with which he won world titles made him the first snooker player to receive global recognition.

The first of the 7 successes at the
London Masters was achieved by Ronnie in 1995, when snooker tournaments were sponsored by cigarette brands, Blur and Oasis were fighting for supremacy in British music, and Eric Cantona proved that he could be a master of karate after the demonstration on Selhurst Park. The final was against another kid. John Higgins was also only 19 years old and was admitted to the tournament with a wild card. Until the final, the Englishman had a hard time. He passed John Parrott, Terry Griffiths and Peter Ebdon. At the Wembley Conference Center, Ronnie had fun. He was 9-3 and at 19 years and 69 days he became the youngest winner in history.

\section{Roger Federer}

Federer is the first tennis player in history to hold 20 Grand Slam titles.

At the 2007 US Open, he won 105 points in a row without any unforced errors, in a match with John Isner.

In 2005 and 2006, he had a record of 53 wins and 2 losses in Grand Slam tournaments.

Between October 2003 and September 2005, he won 24 consecutive finals. The previous record was only 15 (Bjorn Borg).

He did not give up any games on duty in three tournaments he won (Qatar 2005, Halle 2008 and Cincinnati 2012). Federer is the only tennis player to have won a Masters 1000 tournament without losing his job.

He won 26 games in a row (record) against the Top 10 ATP players (October 2003 - January 2005). He won only two matches 6-0, 6-0 in his entire career.

He managed over 10,000 aces in his career. It is surpassed only by Goran Ivanisevich and Ivo Karlovich. He was the number one seed in three consecutive editions of the Olympic Games (Athens 
2004, Beijing 2008 and London 2012).

In 2006, he reached the finals of 16 of the 17 tournaments he participated in, a record for men's tennis; won 12 tournaments.

$\mathrm{He}$ is the only player to have won 7 different tournaments at least 5 times (Wimbledon, US Open, Champions Tournament, Cincinnati, Basel, Dubai, Halle).

\section{Billie Jean King}

Billie Jean was what is called a phenomenon in women's tennis. She started playing at the age of 11 , at 16 she was a professional and at 17 she won her first Wimbledon doubles. He would end his career after 24 years with 12 Slam singles titles (most won at Wimbledon and the US Open), 16 doubles and 11 mixed doubles. He reached number 1 in 1966 and had a total winning percentage of 81\% which brought him 129 titles (67 in the Open era). With an aggressive style of play, based on speed and nets, she is undoubtedly the player who dominated the second half of the $60 \mathrm{~s}$ and the first half of the 70s.

King's contribution is not limited to her achievements on the ground. She fought for the equal rights of women and sexual minorities and to take tennis out of the elitist, white and conservative sports area. In a world ruled by men, Billie Jean was strong enough to change the rules.

Billie Jean King proved that women do not have bigger problems than men with the pressure on the field just because they are women. "Pressure is a privilege" is his most famous quote. Her justice spirit and fierce competitiveness both on and off the field have made women's tennis possible as it is today and have shown girls around the world that there is hope and a way out of a world stifled by inequality.

\section{Conclusions}

Sport has the ability to transform the world, inspire and unite people around the world and grow rapidly in the business environment in a wise way.

Sport has a dynamic effect in the world, as it unites people from all over the world by reducing racism and promoting the internationalization of business.

Many people travel from their country or city to watch some important games, they show the love and passion that people have for sports. Sport plays a significant role in the daily lives of people around the world, for those who actively participate or for those who are just fans and supporters. It has become a vast pastime, occupation, profession and lifestyle and even a good business deal. Nowadays, sport is linked in a universal network of interdependence chains for cross-border transactions, for example the concept of consuming sporting events.

That's why athletes have started to play an increasingly important role in the lives of fans, becoming considered role models.

There are many athletes who have been and will be considered innovative due to the way they play, their personality, the way they interact with the fans during the matches, due to the remarkable results obtained or due to the fact that they were pioneers and achieved what others could not did before them.

\section{Acknowledgement}

All authors contributed equally to this research. 


\section{References}

1. Barbu, M.C.R., Diaconescu, D.L.: Talent management in sport organizations. In: Journal of Sport and Kinetic Movement, 31(1), 2018, p. 62-65.

2. Barbu, M.: Managementul activităţii sportive din România (Sports activity management in Romania). Craiova, Editura Universitaria, 2009.

3. Barbu, M.: Marketing în sport (Marketing in sport). Craiova, Editura Universitaria, 2010.

4. Barbu, M.C.R., Barbu, C.M. and Diaconescu, D.L.: Marketing developments in the sharing economy. In: R. Pamfilie, V. Dinu, L. Tăchiciu, D. Pleșea, C. Vasiliu eds. 6th BASIQ International Conference on New Trends in Sustainable Business and Consumption, Messina, Italy, June 2020. Bucharest: ASE, p. 97-104. Available on: http://conference.ase.ro/pdf/BASIQ_2 020_Conference_proceedings.pdf

5. Barbu, M.C.R., Bratu R.S.: Governance structure of nonprofit sports organizations. In: Annals of the University of Craiova, Economic Sciences 46(1), 2018, p 156-162.

6. Barbu, M.C.R., Burcea, G.B., Dumitru, R. and Popescu, M.C.: The contribution of sport to economic and social development. In: Studia Universitatis Babes-Bolyai Educatio Artis Gymnasticae, 65(1), 2020, p. 27-38. doi:10.24193/subbeag.65(1).03

7. Barbu, M.C.R., Popescu, S.S., and Popescu, M.C.: Sport clubs interaction with the fans using social media communications. Case study at SCM Craiova. In: Studia Universitatis BabesBolyai Educatio Artis Gymnasticae,
64(1), 2019, p. 31-43. doi:10.24193/subbeag.64(1)

8. Barbu, M.C.R., Barbu M.C.: Training of personnel in leadership positions in sport organizations. In: Studia Universitatis Babes-Bolyai, Educatio Artis Gymnasticae, 57(3), 2012, p. 4151.

9. Boyle, R., Haynes, R.: Power Play Sport, the Media and Popular Culture, 2nd Edition. Edinburgh, Edinburgh University Press, 2009.

10. Carlson, B.D., Donavan, D.T.: Human brands in sport: Athlete brand personality and identification. In: Journal of Sport Management, 27(3), 2013, p. 193-206. Available on: https://www.academia.edu/24924309 /Human_Brands_in_Sport_Athlete_Br and_Personality_and_Identification.

11. Cave, A., Miller, A.: Technology in sport: the speed of science. In: The Telegraph, August, 25, 2015. Available on:

http://www.telegraph.co.uk/sponsore $\mathrm{d} /$ business/business-sportseries/11814716/technologyinsport.html.

12. Daugherty, T., Hoffman, E.: eWOM and the importance of capturing consumer attention within social media. In: Journal of Marketing Communications, 20(1-2), 2014, p. 82-102. DOI: 10.1080/13527266.2013.797764.

13. Fried, G.: Managing sports facilities. Champaign, IL: Human Kinetics, 2005.

14. Hall, S.: Effective security management of university sport venues. In: The Sport Journal, (9)4, 2006. Available on: https://thesportjournal.org/article/eff ective-security-management-ofuniversity-sport-venues. 
15. Holmes, K., McLean, R. and Green, G.: Crafting a future online: A study of how independent craftspeople adopt social media and web technologies. In: Journal of Systems and Information Technology, 14(2), 2012, p. 142-154. DOI: $10.1108 / 13287261211232162$

16. Klein, A.M.: Growing the Game: The Globalization of Major League Baseball. New Haven, CT: Yale University Press, 2006.

17. Mossberg, L.L., Hallberg, A.: The presence of a mega-event: Effects on destination image and productcountry images. In: Pacific Tourism Review, 3(3-4), 1999, p. 213-225. Available on: https://www.ingentaconnect.com/con tent/cog/ptr/1999/00000003/f002000 3/art00005

18. Nauright, J.: Global games: culture, political economy and sport in the globalised world of the 21st century. In: Third World Quarterly, 25(7), 2004, p. 1325-1336.

19. Stroe, C.A., Barbu, M.: Impactul sportului asupra economiei (The impact of sport on the economy). Craiova, Editura Universitaria, 2006. 